\title{
Mathematical Practices of Eighth Graders about 3D Shapes in an Argumentation, Technology, and Design-Based Classroom Environment
}

\author{
Sule Sahin Dogruer ${ }^{1}$ (D) Didem Akyuz $^{1}$
}

Received: 16 July 2018 / Accepted: 10 October 2019/Published online: 02 January 2020

(C) Ministry of Science and Technology, Taiwan 2020, corrected publication 2020

\begin{abstract}
This design research investigated the mathematical practices that eight graders (14-year-old students) developed when learning about prisms, cylinders, and their surface areas. An inquiry-based learning environment was created for students to engage in argumentation. The instruction was enriched by use of a dynamic geometry software, namely GeoGebra, to assist students in visualizing and reasoning about 3D shapes. Rasmussen and Stephan's three-phase method (2008) was used to organize the collected data, which in turn were analyzed using Krummheuer's model of argumentation (2015). The results indicated the emergence of three mathematical practices and several taken-as-shared ideas: (1) defining prisms, (2) computing the surface area of a prism, and (3) computing the surface area of a cylinder. The study's results revealed that students' understanding improved when learning concepts simultaneously with argumentation and dynamic geometry software.
\end{abstract}

Keywords Argumentation · Design-based research · Dynamic geometry software · Mathematical practices $\cdot$ Three-dimensional shapes

\section{Introduction}

It is a commonly accepted notion that when students learn mathematics through thinking and reasoning, they develop conceptual understanding. Furthermore, it is commonly

Sule Sahin Dogruer

sule_sahinn@hotmail.com

Didem Akyuz

dakyuz@metu.edu.tr

1 Department of Mathematics and Science Education, Middle East Technical University,

Universiteler Mah. Dumlupinar Blvd, No: 1, 06800 Ankara, Turkey 
assumed that there is a strong relationship between social interaction, children's thinking, and construction of knowledge (Wood, Williams, \& McNeal, 2006). Research has found that learning mathematics includes both personal work and collaborative (i.e. social) work, the latter of which involves discussions within the classroom so that students explain and justify their work to others (Yackel \& Cobb, 1996). Relatedly, argumentation (Brown, 2017) is essential in mathematics classes, and technology-enhanced environments help to facilitate argumentation (Erkek \& Bostan, 2019). As a sub-domain of mathematics, geometry is a subject that can benefit from a classroom environment that supports argumentation, where students can understand geometric structures and theorems, and their relationships, by exchanging ideas. Moreover, by designing instructional sequences enriched with argumentation opportunities, teachers can give students a chance to communicate their ideas with others. Argumentation conducted within a specific learning context allows students to transfer and foster taken-as-shared ideas, which are ideas that help construct mathematical practices (Cobb, Yackel, \& McClain, 2012). This study examines classroom mathematical practices that were formed by an instructional sequence on prisms, cylinders, and their surface area, based on an earlier instructional sequence created by Stephan (2015).

\section{Literature Review}

\section{Argumentation}

Researchers have devoted much attention to the interplay between students' interactions in the mathematics classroom and their learning of mathematics (Krummheuer, 2015). In design-based research, it is critical to evaluate how learning occurs in a social community (Cobb, 2000). A classroom that facilitates mathematical argumentation provides opportunities for students to think aloud and explain how they think (Yackel $\&$ Cobb, 1996). This kind of learning environment allows students to interact with one another and develop conceptual understanding. Argumentation involves constructing claims, providing evidence to support the claims, and evaluating such evidence to judge the validity of the claims (Schwarz, Hershkowitz, \& Prusak, 2010). Studies about mathematics education suggest that students' participation in argumentation promote a meaningful understanding of mathematical concepts (Ayalon \& Hershkowitz, 2018; Mueller, Yankelewitz, \& Maher, 2014).

Wood and Turner-Vorbeck (2001) examined class cultures and found that effective teaching should include children's participation and an openness for different thinking types. However, teachers must understand argumentation to engage students in such activities (Mueller, Yankelewitz, \& Maher, 2014). They must know about mathematically acceptable justifications, students' common errors, misconceptions, and difficulties related to argumentation, and the conditions necessary to build an active argumentative classroom environment (Ayalon \& Hershkowitz, 2018).

Wood and McNeal (2003) also emphasize the importance of a classroom culture that promotes argumentation. According to them, in conventional classroom culture, mathematical thinking mostly includes recalling prescribed procedures and student participation includes telling the right answers. There is little, if any, room for argumentation. In the reform classroom culture, the students' responsibility for thinking increases, the students become more active participants, and they not only justify and defend their 
solutions but also start to ask questions for understanding and clarification. The teacher becomes the facilitator for effective argumentation.

\section{Mathematical Practices}

In the literature, various studies have focused on mathematical practices (Cobb, Stephan, McClain, \& Gravemeijer, 2011; Stephan \& Rasmussen, 2002). Moschkovish (2002) divided mathematical practices into two groups. The first group was defined as everyday mathematical practices and included mathematical activities used in the course of daily life, such as those used when shopping and ordering. Moschkovich called the second group academic (also known as classroom) mathematical practices, encompassing activities that occur in the school environment, such as giving mathematical presentations and solving mathematical problems. Academic mathematical practices emerge in the classroom through mathematical argumentation (Cobb et al., 2011). Since mathematical practices develop during whole-class argumentation, each student's participation affects these practices. Students contribute to mathematical practices by reasoning on a specific topic (Cobb et al., 2011). Consequently, the same topic taught to a different group of students may bring forth different mathematical practices.

The emergence of mathematical practices is typically observed through students' participation in the classroom discussions. For this purpose, Rasmussen and Stephan (2008) have developed a methodology that uses Toulmin's model of argumentation (Toulmin, 1969). This model of argumentation is adapted for analyzing classroom mathematical discussions by Krummheuer (1995). This scheme involves transcribing the classroom discussions and looking for evidences of data, claims, warrants, and backings. As students' arguments change position between these categories, such as for instance when a previous warrant now becomes data, and such shifts are not confronted by other classroom members (despite socio-mathematical norms having been established (Stephan \& Akyuz, 2012)), these arguments are accepted as taken-asshared (TAS) ideas (Cobb, Yackel, \& Wood, 1992). The term taken-as-shared reflects the fact that while absolute interpretation of these ideas in each individuals' mind cannot be ascertained, they nevertheless constitute a collectively agreed upon, thus shared, way of communicating within the classroom. A related group of such ideas can be categorized under what is known as a classroom mathematical practice. Extraction of mathematical practices for classroom teaching experiments is important as they open a window into the collective learning that has occurred within a classroom.

\section{Geometry and 3D Shapes}

For many years, educators and researchers have studied how geometry is taught and learned. They revealed that students have difficulty in learning geometry and suggested some prerequisite reasoning abilities to overcome their challenges (Mason, 1998). Researchers stressed the importance of visualization among these prerequisite abilities (Duval, 2000; Gutiérrez, 1996; Laborde, Kynigos, Hollebrands, \& Strässer, 2006).

In geometry lessons, students work on spatial objects, such as $2 \mathrm{D}$ shapes and 3D solids; relationships, such as equality and parallelism; and transformations, such as reflection and rotation (Clements, 1999). To make these concepts clear for students, 
teachers question students about visualization techniques and present various representations, such as drawings, schemes, and graphs (Kosko, Rougee, \& Herbst, 2014). These representations provide contextual descriptions of geometric concepts; they support students' conceptual understanding and help students develop their geometric reasoning (Denbel, 2015).

Three-dimensional thinking and reasoning is considered to be difficult by learners (Adolphus, 2011). Therefore, recent studies have begun to evaluate students' reasoning about geometry and 3D shapes by using dynamic geometry environments (Akyuz, 2016; Morgan \& Alshwaikh, 2012; Ng \& Sinclair, 2015) as they allow interacting with and visualizing geometrical objects from different viewpoints. Various studies discuss students' understanding about 3D shapes, misconceptions and errors, and the ways for improving students' conceptual understanding of the context (Wright \& Smith, 2017).

Other studies also highlight the importance of a proper use of computer in mathematics education to help students achieve high-level cognitive skills (Hollebrands, 2007; Leung, 2011; Sack, 2013). It is envisaged that dynamic geometry software, which reflects the rapid developments of computer technology in geometry classes, can help mathematics education to achieve these goals (Oldknow \& Tetlow, 2008).

\section{Theoretical Framework}

Though similar to emergent perspective (Cobb \& Yackel, 1996; Cobb, 2000), in this study, we interpreted students' mathematical development by only focusing on the collective activity of the students and did not consider specific individuals' activities. In other words, we observed the development of mathematical practices as evidenced by social interactions. To this end, our analysis differed from Saxe, de Kirby, Le, Kang, and Sitabkhan (2015), who analyze both collective and individual activity.

Focusing on collective activity for extracting mathematical practices is not uncommon (Cobb et al., 2011; Stephan \& Akyuz, 2012). It is however crucial that the classroom in which such analysis is made adheres to social and socio-mathematical norms. Social norms refer to acceptable ways of communicating within the classroom, while socio-mathematical norms define the rules of mathematically acceptable discussions (Yackel \& Cobb, 1996). To this end, the teacher in the current study encouraged the students to explain their ideas as well as their agreement and disagreement, told them to represent their work clearly, and encouraged them to comment on their peers' solutions. Additionally, the teacher supported socio-mathematical norms by encouraging different solutions, explanations, justifications, and making conjectures.

\section{Method}

\section{Design-Based Research}

Design-based research is concerned with the development of research-based solutions for complex problems in educational practice by developing and testing theories of learning and teaching processes. In the design study, the research process always involves systematic educational design processes (Plomp, 2013). All systematic education and training processes are cyclical because they involve design, analysis, 
evaluation, and revision activities, and this process continues until reaching a proper balance of interest (Plomp, 2013). Authors may use a variety of illustrations for picturing the details of design-based research, but they generally agree that it has several phases (Plomp, 2013). For example, Cobb (2003) mentions those phases as preparing for design experiment, conducting design experiment, and later retrospective analysis. Also, a variety of researchers used the same categorization in their reports (Graveimejer \& Cobb, 2013). In this study, we used an instructional sequence on prisms, cylinders, and their surface area developed by Stephan (2015).

\section{Krummheuer's Argumentation Model}

This study uses Krummheuer's argumentation model (Krummheuer, 1995; Krummheuer, 2007; Krummheuer, 2015) as a tool to analyze the classroom discussions. Krummheuer analyzes argumentation using Toulmin's (1969) scheme of data, conclusion, warrant, and backing. According to the scheme, the conclusion is a statement that needs to be proven; it is a claim. If one gives support to the conclusion, that is data. The warrant is an explanation of why the data are considered to provide support for the conclusion. Backing refers to providing further support for the warrant with undoubtable convictions (Krummheuer, 2015; Yackel, 2001).

By this model, Krummheuer explains how an argumentation occurs as an interactive construct of social community. This interaction consists of possible class social interaction and discourse that students actively participated in. From this perspective, individuals are seen as creating information by being involved in interpersonal activity to access the mathematics obtained as a common knowledge (Wood \& McNeal, 2003).

\section{The Context of the Study}

The present study was designed around the context of the basic features and elements of prisms, the surface area of rectangular prism, and the surface area of the cylinder. The instruction was supported by using GeoGebra and active argumentation within the classroom. A hypothetical learning trajectory (HLT) was created as an important element of design research (Simon, 1995). The HLT included the learning goals, planned activities to support these learning goals, and an overall consideration of the teaching and learning process throughout the instruction.

While forming the activities, Stephan's (2015) instructional sequence was used as the main resource. This instruction sequence was comprised of three main phases. The aim of the first phases' activities was to construct an understanding and identification of common properties of perpendicular prisms. Next, the sequence continued with the views of prisms from different viewpoints. Following these activity sheets, "candy wrapping company" was used as context (Stephan, 2015). Each shape was designed with unit squares on it to make students understand those unit squares can be used to compute lengths and areas. We have enriched this part of the instructional sequence with relevant GeoGebra activities.

The learning objective for the second phase was constructing "the formula of the surface area of perpendicular prisms". First, shapes of the activities were given with unit squares on them and the students were asked to find out "how they can wrap those candies by using wrapper papers?" and "how many unit squares would be there?" 
Working on those questions, the aim of the activity sheets was to make an introduction to the surface area of the perpendicular prisms. After being asked various questions about unit squares, students worked on activities that included shapes without unit squares. With those questions, students were expected to make connection between unit squares and length of the edge of a shape. With the support of GeoGebra files for each activity sheet, students had a chance to visualize their solutions.

Next, the students were asked to work in pairs to produce a formula for perpendicular prisms. Here, the important point was students' abilities of transforming their numerical work into algebraic expressions. They worked on various activities by solving them and then worked on expressing the processes algebraically. This was a challenging process for students to transform that kind of numerical knowledge into algebraic expressions, also to understand "how to name any length with a letter or a character". So, additional activites were added at this point.

The third phase was planned related to the learning objective of "determining the basic elements of cylinder, constructing, and drawing the net of it." The process started with the teacher's questioning students about what a cylinder is and asking them to give daily life examples of cylinders. Next, the students were asked to draw a wrapper of cylinder candy which tried to evaluate whether students understood the aim of the question which was "what the net of a cylinder is?" After whole class discussion sessions ended, the GeoGebra file was opened to check their answers and to evaluate the relationship between the changes of lengths of closed shape and opened shape. After constructing the knowledge of basic elements and net of a cylinder, the other step of the activity sheet was about constructing students' understanding on circumference of one base cylinder, which equals to the length of the edge of its side surface on which it was wrapped. By working on it, students were expected to use that knowledge as data for classroom discussion. Another aim was to make students to transfer the knowledge between the different lengths of the cylinder. For example, they were expected to be able to find the length of the radius if they knew the length of the edge on which it was wrapped and vice versa. Throughout this phase, the students were expected to have knowledge base for the next part, which was about the surface area of a cylinder. Students' reasoning on finding and understanding how to wrap those cylinder-shaped candies was critical for forming a formula for the surface area of a cylinder. Next, students were asked to transform their numerical work into algebraic expressions as was done before.

It is important to note that in most of the activities, GeoGebra was not simply used as a static presentation tool but rather as a dynamic exploration environment. This allowed the students to change the activities dynamically and observe the effect of their changes on the 3D objects. For instance, in one activity, the students, by means of a slider, could change the number of sides of the base shape and observe how this affects the side faces and the overall shape of the object. In another activity, the students could open a shape by varying amounts to observe the gradual transition from a 3D object to its net. Most of the activities had dynamic features similar to these examples (Fig. 1).

\section{Data Collection}

The study was conducted in the eighth grade (14-year-old students), a public middle school in Turkey. The participating classroom consisted of 16 girls and 19 boys. The 


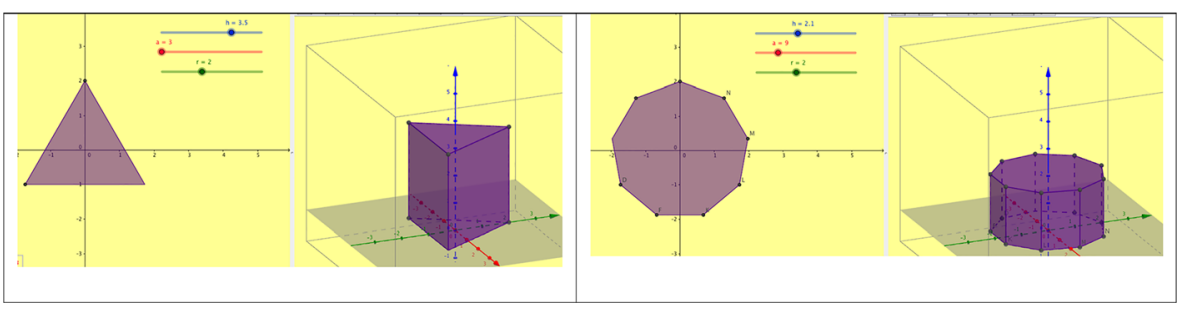

Fig. 1 Examples of DGS activities used in the instruction

study was conducted in a four-and-a-half-week instructional sequence and seven classhours in each week (one class-hour was $40 \mathrm{~m}$ ). The participating classroom learned in a social environment designed according to the requirements of the discursive classroom through an instructional sequence in which they engaged in geometrical issues alone or with their peers in small groups and by participating in whole-class discussions.

Stephan's (2015) work named "Surface Area" constructed the base while forming the activities as detailed in the previous section. Other activities were derived from the website of the Ministry of National Education and students' textbooks. While ordering the activity sheets, students' thinking levels and learning goals derived from the national curriculum were considered. Essential activities were adopted to the DGS (i.e. GeoGebra) environment.

The data corpus consisted of (a) classroom-based data, which include videotapes of all lessons, detailed field notes from the learning environment, copies of all students' written works and (b) audio-records of discussions from the meetings of school research team. The school research team shared their ideas and experiences in the instructional sequence during the weekly meetings. Also, the researcher and the participating teacher met after completing the teaching-learning session of each course-objectives defined in the national curriculum.

Three course objectives were covered during the study. These learning objectives were defined in the National Mathematics Curriculum as (1) [Student] identifies the right prisms and determines their basic features, elements, and draws the nets, (2) [Student] identifies the basic elements of a right circular cylinder and its net, and (3) [Student] constructs the formula of surface area of right circular cylinder, solves related problems.

The research team met four times for weekly discussions and three times after each course objective. Those meetings were about what was happening in the classroom sessions regarding the instructional sequences; any problems, possible misconceptions, or any wrong-learnings in them; what would be possible solutions to them; what content could be removed aligned with the principles of design-based research. The main instructor was the participating teacher, and the researcher interacted with all the participant of the study as much as possible in their natural settings (Fraenkel, Wallen, \& Hyun, 2014).

\section{Data Analysis}

A detailed analysis of classroom practices was conducted to identify the learning process. To analyze data in this way, Rasmussen and Stephan (2008) have developed 
a three-phase method to document taken-as-shared ideas and mathematical practices. This method is useful for the organization of the data set, and it reveals how the process's taken-as-shared ideas become mathematical practices. Each phase required different actions in themselves.

In the first phase, the process started by creating transcripts of whole-class discussions. Then, the researcher watched all the video records and took notes for claims (conclusions) that were made by the teacher or any of the students. To provide reliability, the participating teacher also produced her own argumentation log. Afterwards, the researcher and the teacher met to discuss about their works of analysis and compared the two argumentation schemes. By discussing on the data, conclusion, backing, and warrant issues, they came to agreement on the argumentation scheme at the end. In the analysis, Krummheuer's (1995) argumentation method was used as a tool to systematically analyze argumentations.

The second phase sees the argumentation log as data set itself and looks for whether the mathematical thinking became the groups' way of sharing their ideas normally. To understand this, Rasmussen and Stephan (2008) defined two criteria as (1) when any backing or warrant does not occur in the students' explanations (which means that no one in the classroom have a challenge about that argument, the mathematical idea became self-evident in the discussion), and (2) the use of a previously justified conclusion or claim was used as data in subsequent discussions (which means that mathematical idea become the group's one of the ways of expressing thoughts).

For the third phase of the analysis, by obtaining the taken-as-shared ideas, related classroom mathematical practices were produced. The ideas from the shared chart and the mathematical ideas were reorganized by labeling them as common mathematical activities if they occurred by the participation of the whole classroom, and they were named as classroom mathematical practices (Rasmussen \& Stephan, 2008).

\section{Findings}

Using the analysis described in the previous section, the current study obtained several taken-as-shared ideas and three mathematical practices (Table 1). These were (1) finding the definition and properties of prisms, (2) finding the surface area of prisms,

Table 1 The mathematical practices and taken-as-shared ideas emerged in this study

Practice 1: defining prisms

- TAS1: The roof of buildings and tent shapes are prisms.

- TAS2: A cube is a prism.

- TAS3: The base shape affects the other parts and overall shape of a prism.

- TAS4: A cylinder is not a prism.

Practice 2: computing the surface area of a prism

- TAS1: Wrapping means drawing the net of a prism.

- TAS2: Counting unit squares to find the surface area

- TAS3: Producing the formula for the surface area of prisms

Practice 3: computing the surface area of a cylinder

- TAS1: The net of a cylinder contains two circles and one rectangle.

- TAS2: Circumference of the circular base is equal the length of one edge of the rectangle.

- TAS3: The height of the cylinder is equal to the length of the other side of the rectangle. 
and (3) finding the surface area of the cylinder. In the following, these practices are elaborated in greater detail with excerpts from classroom discussions. As our primary goal in this article is to document the emergence of the mathematical practices and that these practices are underpinned by taken-as-shared ideas, we selected excerpts from the data that illustrates the emergence of these taken-as-shared ideas.

\section{Practice 1: Defining Prisms}

At the beginning of the instruction, the classroom was discussing daily life examples of prisms. One student gave an example as the roof of buildings and camp tents were prisms. Later, in advancing hours of the instruction, another student criticized that idea by pointing out the earlier example about roof and tent (all names are pseudonyms):

\section{Eda: Can I ask a question?}

Teacher: Yes.

Eda: I think that roofs are not prisms, aren't they?

Teacher: One minute. Eda asked a good question. She is not sure about whether the roofs are prisms or not.

Eda: Because, if we look at Aydin's claim, they should have top and bottom bases, but roofs do not have that kind of property.

Teacher: What do you say? What's your idea? She states based on what Aydin said, prisms should have the same bottom and top bases. However, she says roofs do not look like that.

Eda: Roofs have bottom bases, but other edges merge at the top point of the roof, don't they?

Teacher: Yes, what do you think? Are roofs prisms or not? [Class responds no]

In this episode, Eda questioned that whether a roof was a prism by referring to Aydin's claim about prisms should have top and bottom bases, but roofs do not have that kind of property. Instead of immediately telling the right answers, the teacher encouraged students to express their ideas, which was very important for sustaining the social norms. In general, students remembered from prior knowledge that the prisms had the same top and bottom bases. Nearly, the whole class was sure that roofs and camp tents were not prisms since they did not have top and bottom bases. Students were having difficulty to understand that a tent or a roof was also a prism. This problem was based on the students' visualization problem about the position of a prism. They could not visualize the place of the top and bottom bases in their minds when it was placed horizontally. At this point, the teacher asked questions and also asked for justification. As it can be seen from the discussion, the responsibility for participation was high. Eda asked questions for understanding and clarification. In other words, both the teacher and the students were active listeners. The conversation continued as follows:

Teacher: Let's look at the characteristics of those examples you said. For example, looking at the bookcase or a matchbox, what can you say? Think about this. What are the features?

Arda: They have corners.

Teacher: Good. They have corners. What else? 
Berna: They have edges.

Mert: They have side faces.

Teacher: They have side faces. Let's compare those faces. Where do you see those faces? Eda.

Eda: At the bottom and the top. Also, also, they have side faces.

Ece: Those bottom and top bases are parallel to each other.

Teacher: Excellent. She explained that the bottom and top bases should be parallel.

Melisa: They have heights.

Teacher: Good. They have heights. You said top and bottom bases. Side faces. Let's look at your example roof and camp tents. Do they have faces?

Aydin: Yes. They have side faces.

Teacher: What about the top and bottom bases?

Aydin: They do not have.

Melisa: But, why we cannot say tents or roofs are prisms? They have the same shape on both two sides. I say, one side is a triangle in a roof, and it also has the same triangle another side.

Teacher: You say, it has two triangle faces. So, she asks why we cannot call it a prism.

Class: (Silence)

Teacher: Ok. I want you to see this illustration. (Teacher opens a GeoGebra file).

While discussing the features of the examples given by students, Ece raised a valid property of prisms as the parallelism of the top and bottom bases. However, by referring to the previous discussion, Melisa challenged the idea of roofs and tents not being prisms. Here, again it was observed that students were active listeners as they were disagreeing to their friends and challenging their ideas. She justified her idea by stressing that the top and bottom bases are two equal triangles. At this point, the researcher opened a GeoGebra file illustrating a triangular prism shape as shown in Fig. 2.

Teacher: Now, what do you think about the issue? Do roofs and tents have top and bottom bases. Is there any change in physical features of this shape when we turn it up?

Eda: It is still a roof or a tent, there is no change.

Teacher: Yes, Melisa.

Melisa: The shape has the same features as other examples on the board. So, it has the features of being a prism. It has two equal bottom and top bases, it has height, and it has side faces.

Aydin: Those bases are parallel to each other.

Teacher: So, what is the decision about the roofs and tents?

Aydin: They are also prisms.

Teacher: Yes, they are prisms. What kind of prisms are they?

Class: Triangular prisms.

Teacher: Is there any missing point here? Is there anyone who doesn't understand? 


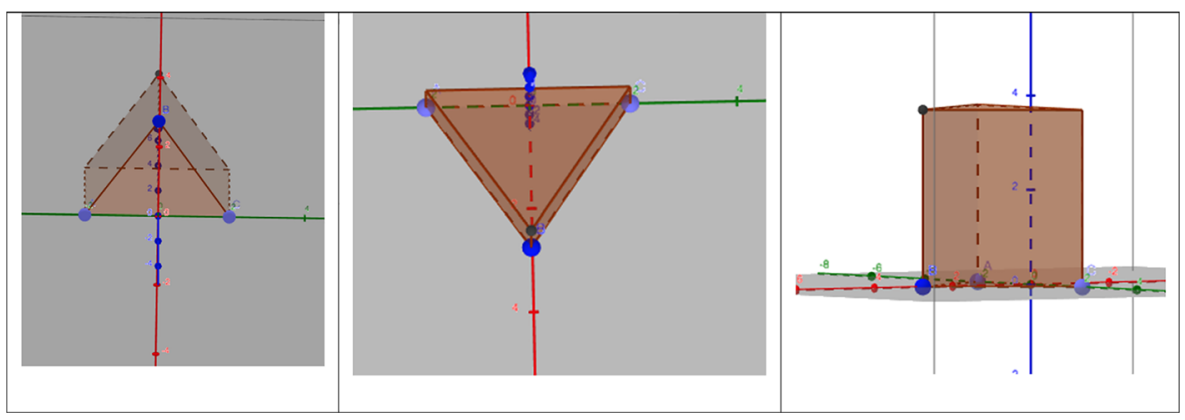

Fig. 2 GeoGebra file for a triangular prism

After demonstration of the shape on the GeoGebra file, Aydin claimed that it was a prism with data from Melisa and a warrant from Aydin. During the discussion process, the students formed the mathematical idea about "what the definition of a prism is" based on the examples given by them and based on the comparison of those examples according to their characteristic features. Here, it is important to note that the teacher supported mathematical thinking by asking questions and elaborating students' solutions. The process continued under the guidance of the classroom teacher, and at the end of the process, none of the students challenged the idea. This was facilitated by use of GeoGebra as it allowed the students to observe this shape from a different viewpoint. The students could see that the roof/tent shape when rotated sideways up has the prototypical appearance of a prism. It was observed from first Melisa and Aydin's arguments and then the collective response of the classroom that idea of "the roof of buildings and tent shapes are prisms" became taken-as-shared. The other taken-asshared ideas that constitute the first mathematical practice were developed in a similar manner.

\section{Practice 2: Computing the Surface Area of a Prism}

A wrapper factory concept (Stephan, 2015) was used to cover the candy produced in specific forms. In this factory, the produced candy wrappers were priced over the unit squares; in fact, by this way, both the nets of the prisms and the calculation of the surface area were introduced.

Teacher: As you read, this question wants you to create a wrapping paper for the cube-shaped candy. What do you think about this?

Hakan: Actually, the question asks the net of the cube.

Beyza: Yes, it asks the net of the prism. We did it in previous years.

Teacher: Exactly, it is about the net of the prism.

This section started with the teacher's questioning of the students about whether they understood the question, which was asking net of the cube. In this context, Hakan and Beyza replied the question as shown in the excerpt. For this question, students worked individually. During the process, the teacher visited the students to check and help with any challenge. The following step was to draw wrappers for the given candies in 
different shapes such as the triangular prism, pentagonal prism, and hexagonal prism. The students were given about $10 \mathrm{~min}$ to draw the wrappers for those solids. While students were working on the question, the researcher and the teacher visited them. After the classroom completed the process, they checked their drawings from GeoGebra (Fig. 3). During the process, the following conversation occurred between the students and the teacher.

Teacher: With this page, you are expected to draw wrappers for candies in given shapes. What it wants you to draw?

Arda: Their nets again.

Teacher: Exactly, right. You are expected to draw their nets.

As illustrated by this discussion, it became clear that the idea of wrapping a shape means to draw its net ${ }^{1}$. This idea was assumed to become taken-as-shared among the students. This conclusion is reached by Hakan and Beyza's arguments in the previous discussion and Arda's comment in this discussion. The idea of "wrapping means drawing the net" seemed to be accepted by the classroom members as it was used as a "claim" that did not require warrants or backings.

In this part of the instruction, the aim was not only to design one piece of wrapping paper for a candy but also to calculate how many square units of the wrapping paper was used. The candies given to the students for this part were initially built using unit cubes. In later steps, it was questioned the need of wrapping paper for each prismshaped candy constructed without unit cubes:

Teacher: I want to listen to your solutions. Yes, Arda.

Arda: I counted squares as Aydın. Here, six times three, there are 18-unit squares on the front side. And at the back side as the same, 36 in total. On the top of the shape, there are six times four there are 24 and 24 from the bottom. There are 48. On the right side, four times three, there are 12 and at the left as the same. 24 in total. And totally, there are 108-unit squares.

Teacher: Yes, you did the same as Aydın. Do you want to add something? Is there anything wrong?

Selin: I also counted the squares.

Arda stated that he used the same way as Aydin used for the previous question. This discussion was not the last example of counting or calculating the number of unit squares. In most activities of this part, students chose to use counting unit squares. Here, students listened to Arda and they decided if their own strategy was different than him, which suggests that they were active listeners. Arda's idea was mathematically acceptable and became taken-as-shared in the classroom environment when evaluated using Krummheuer's model of argumentation. Thus, it was concluded that the usage of

\footnotetext{
${ }^{1}$ Although we did not notice any sign of confusion for computing the net by wrapping a shape, it should be acknowledged that in the physical world where wrappers cannot be infinitely thin, a wrap becomes slightly larger than the actual net of a prism.
} 


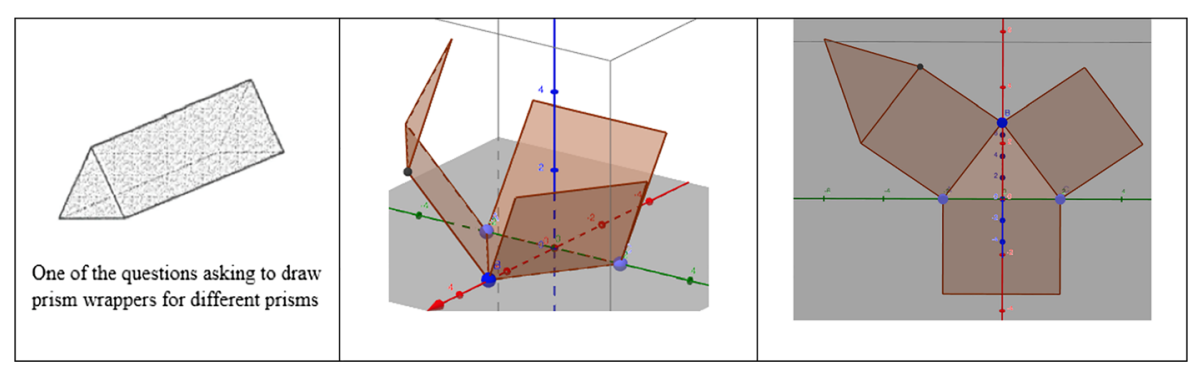

Fig. 3 A triangular prism and its GeoGebra view

counting unit squares became a taken-as-shared idea (as a step for the surface area of prisms) while calculating the area of wrappers.

After working on the calculation of the prisms' surface area of shapes constructed by unit cubes, the classroom worked on producing the formula for the surface area of prisms. The example shown in Fig. 4 was expected to offer a clue for students. This section was about some students' work on producing a formula for the surface area of prisms. After the students worked on their formula, they were also expected to discuss those solutions.

After the work was completed, the teacher wanted the students to explain their ideas on the board. First, Aydin explained his way. In the following, his solution and explanations are given for a rectangular prism:

Teacher: Yes, Aydin explain your way.

Aydın: I named the edges as a, b, and c. Then, I found the area of each rectangle as we did before. One face is ba, and there are two, so it is $2 \mathrm{ba}$. Another face is cb, there are two, so it is $2 \mathrm{cb}$. And this face is ca with the back side; it is $2 \mathrm{ca}$.

Teacher: Then you summed all up.

Aydın: Yes. I summed up like this $(2 \mathrm{ba}+2 \mathrm{cb}+2 \mathrm{ca})$.

Aydin calculated the area of each face, then he multiplied by two, and at the end, he summed all them up to produce his formula. After his explanation, Zeynep came to the

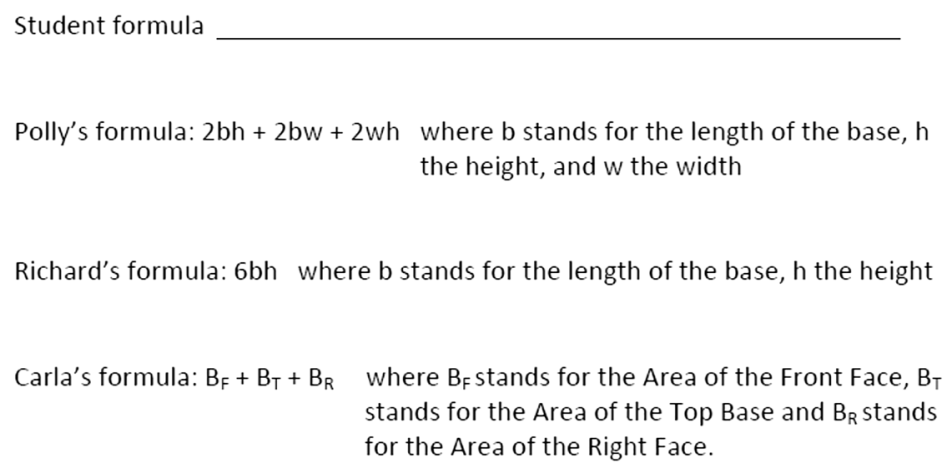

Fig. 4 The clue for students about the surface area formula (Stephan, 2015) 
board and explained her approach which involved multiplying the sum of areas by two, i.e. $2(a c+b c+a b)$. Zeynep concluded that her solution was similar to Aydin's but multiplication was performed at the end. Students were also asked to observe the dynamic change in a rectangular prism's surface area when its sides were resized by means of sliders (Fig. 5).

Here, it is important to note that Zeynep listened to Aydin and decided whether her strategy was different than him. This showed that the socio-mathematical norm of finding different mathematical solutions was sustained by the classroom members. Aydın's and Zeynep's explanations about summing up rectangles' area seemed to be accepted by the classroom since there were not any challenges, any warrants, or any questions about it. Thus, it can be concluded that the idea for the surface are formulate became taken-as-shared contributing to the emergence of the second practice.

\section{Practice 3: Computing the Surface Area of a Cylinder}

The third mathematical practice was about finding the surface area of a cylinder. The classroom studied on the net of the cylinder, its features, elements, and the surface area. The first exercises included drawing a wrapper for a cylinder-shaped candy, and then they worked and discussed the net of the cylinder and its parts. This step was important for students to understand the relation between the circle bases and the rectangle side face of a cylinder. After working with various examples and questions, the students continued to find the area of the given cylinders separately. Then, they moved on to think about the surface area of a cylinder and to produce a formula for it. The first section was about designing a wrapper for a given cylinder-shaped candy box.

Teacher: Your drawings were excellent. So, what did you understand from this question? What is the main idea?

Burcu: It is questioning us about which pieces a cylinder includes.

Teacher: Yes. Any other ideas? Say, Kaan.

Kaan: We can see that a cylinder is constructed by a circle and rectangle.

Teacher: Yes, anyone else?

Beyza: It is about the net of the cylinder.

Teacher: Yes. The question wants you to see the parts of a cylinder and its net.

By working on the net of the cylinder, the students learned the shapes of its pieces. They discussed their relationships. Afterwards, the teacher questioned the classroom about the height of the cylinder. She tried to make them aware of how the height of a

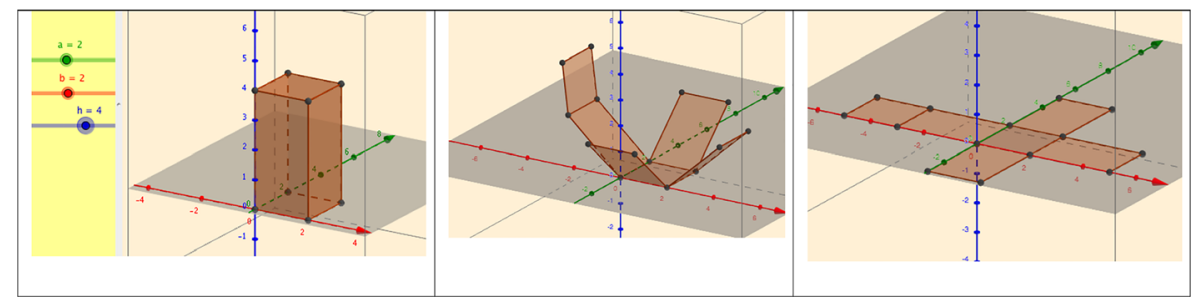

Fig. 5 Observing the change of a rectangular prisms' surface area when its sides are dynamically changed 
cylinder changes depending on the lengths of the side face edges and related to the circumference of the circles:

Teacher: Now, I want you to think about the height of the cylinder. GeoGebra file will help you. Look at that net of the cylinder. Where is the height of the cylinder? Which length indicates the height of the cylinder? Yes, Melisa.

Melisa: Looking at the shape, we see that this edge is the height of the cylinder.

Teacher: What is that edge?

Melisa: It is the short edge of the rectangle. It is the height of the cylinder.

Researcher: Does the short edge need to be the height of the cylinder? Is it always okay? What do you think?

Zeynep: If we have a long cylinder, the height will be the long edge. It depends on the given lengths and circle bases. We cannot conclude that the short edge is the height of the cylinder.

In this section, the classroom evaluated the relationship between the closed and open form of a cylinder by the support of a GeoGebra activity (Fig. 6). The use of GeoGebra in this process allowed students to see the transition of the cylinder from the open to the closed form. Students could easily associate the height of the cylinder with one edge of the rectangle. In the following questions, the closed form of the cylinder was given with height and radius information. By using that data, the students tried to find the area of the circle and rectangle. These questions were prepared based on the previous section which was about understanding the relationship between the circle bases and the side face. The questions had some data on the closed form and were asking about their nets and vice versa.

Teacher: Deniz will come for the first one.

Researcher: Please explain your reasons while solving the question.

Deniz: We find the area of the circle by using $\pi$ as 3 . Also, the radius is 0,5 . Then, $\mathrm{r}^{2}$ is 0.25 . Thus, when multiplying them all, it is 0.75 .

Teacher: And that area?

Deniz: And to find the area of the rectangle, we need the short and long edge. The area is found from their multiplication.

Researcher: So, what did you do?

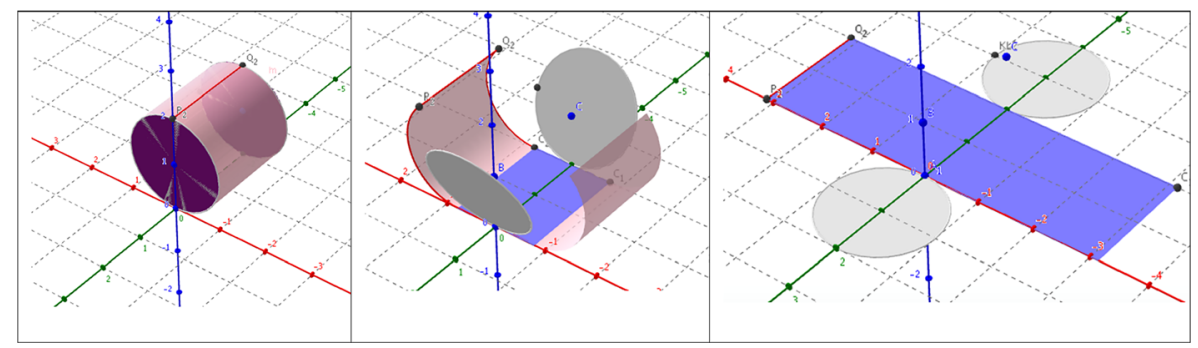

Fig. 6 Net of a cylinder visualized with GeoGebra 
Deniz: As we talked in previous lessons, we find the long edge by using the circumference of the circle base. Thus, it will be found by $2 \pi \mathrm{r}$. It is 3 . The height of the cylinder is the short edge of this rectangle. Thus, three times two is 6 .

Teacher: Is there any comment on Deniz's way?

Kerem: As we did in previous lessons, we have two circle bases and one quadrilateral side face. If we think like wrapping as candies, we need to find the area of wrappers. We will find the area of the circle and the area of the side face.

Teacher: Kerem supported Deniz's claim. Do you agree with them? [Class responds yes]

In this discussion, Deniz first found the area of the circle and then the area of the rectangle. To find the area of the rectangle, he used the circumference of the circle and the height of the cylinder. Kerem supported his claim by stating that a cylinder is constructed by two circles and one quadrilateral as a side face. Additionally, he used one of the previous ideas that the side face of a cylinder should be a quadrilateral shape.

There were two more questions about the same concept. These questions required the students to find the area of the circle bases and the rectangle side face of cylinders given in open forms (by working on their nets). Thus, they evaluated the main idea of how to calculate the surface area of the cylinder by deducing it from its net. Also, in this process, the use of the previous ideas was essential to get a conceptual understanding of what a surface area is and how to calculate it. When we considered the classroom discussions above, the students provided reasons and challenged their friends if they did not understand. Thus, they were active listeners and their mathematical thinking included constructing, analyzing, and evaluating. In other words, students' responsibility for thinking as well as for participation was very high in all classroom discussions, which resulted in the emergence of the final mathematical practice.

\section{Discussion}

This study combined elements of three modern teaching approaches, namely designbased research, argumentation, and dynamic geometry software to teach eight grade students about 3D shapes and their properties. All of these three components were found to contribute to students' learning, and it was generally observed that students were highly motivated to participate in this learning experiment. It is not typical in conventional mathematics classrooms to use these teaching approaches simultaneously, let alone individually (Wood \& McNeal, 2003). Therefore, the results of this study can provide insights for teachers who want to implement similar strategies in their own classrooms. Below, we discuss how each of these elements played role in students learning.

\section{Argumentation}

While the classroom was working on a question as an introduction to the surface area involving a rectangular prism constructed by unit cubes, they involved in a whole-class discussion about the related question. One of the students explained her way of 
thinking for the solution, and another student accepted her solution and explained his way. Both of them did the same things, but they used different strategies. When a third student confirmed the validity of both strategies, the solution was accepted. Consistent with the nature of argumentation, the students accepted/justified another's idea and constructed their explanations on others. This process was facilitated by the social norms of explaining and justifying one's solution and solution process, and also making sense of other students' solutions (Yackel, 2001).

An argumentation classroom includes strategies for reporting and inquiry. A disagreement or a challenge from other students and from the teacher can start a change in students' thinking (Wood \& McNeal, 2003). For example, at the beginning of the instruction, while discussing and defining prisms, some students provided inappropriate examples and stated mathematically unacceptable definitions for prisms. By being involved in an argumentation process during the instruction, they identified the missing points, inappropriate examples about the prisms, and they corrected themselves by expressing, commenting on, and justifying or refusing other's ideas with the support of the teacher's directions.

As another example, during the introduction of the surface area, the instructional sequence was prepared to include shapes constructed by unit cubes as a first step. In later questions, the shapes were not constructed by unit cubes. The aim was to make students understand the idea of one edge of a unit cube equals to one unit of measurement (such as one centimeter). By arguing and exchanging ideas, the students made appropriate and acceptable mathematical explanations. They stated that instead of counting all the unit squares, they could multiply each edge with the other, as they do while calculating the area of a rectangle. This was a mathematically acceptable and an efficient solution and is considered as an important socio-mathematical norm in the literature (Yackel \& Cobb, 1996; Yackel, 2001).

\section{Dynamic Geometry Software}

It was observed that the use of GeoGebra as an instructional tool supported students' conceptual understanding of three-dimensional shapes. The students could interact with the shapes and observe them from different viewpoints. This allowed students to become aware of their properties that are difficult to observe, and therefore often memorized, in a purely paper-and-pencil environment (Owens, 2014). This helped them to develop ideas that became mathematically acceptable ways of communicating in the classroom, paving the way for development of classroom mathematical practices. Moreover, consistent with the literature, the use of DGS provided a richer learning environment for geometry than using paper-and-pencil alone (Battista, 2007). It gave an opportunity to students to explain and prove their thinking and reasoning, ultimately resulting in the development of classroom mathematical practices. Various studies in the literature report findings in the same direction (Clements, Sarama, Yelland, \& Glass, 2008).

\section{Design Research}

Consistent with the tenets of a design-based study, another important aspect of the study was to implement and modify the instructional sequence and prepare the next 
iteration of the instructional sequence according to the students' needs. To provide an effective instruction, the research team decided to change the order of some of the content while the instruction was in progress. For example, in the original instructional sequence, the different views of the prisms were coming after drawing wrappers for them (Stephan, 2015). According to the dialogues that took place in the classroom, changing their order was found to be more appropriate. Also, it was observed that students' visualization of the three-dimensional shapes could improve if they were allowed to work with GeoGebra files that visualize the shapes from different viewpoints.

\section{Student Learning}

There are many ways to assess student learning. In this study, the primary source of assessment was the emergence of the mathematical practices together with their constituent taken-as-shared ideas (Rasmussen \& Stephan, 2008). These can be considered as "big-ideas" that are collectively discovered by the classroom community. If these "big ideas" capture the important aspects of the topic it can be concluded that the teaching experiment was successful. Although not detailed in this article, in practice, other quantitative assessment strategies were also used and they produced positive results in terms of student learning.

\section{Conclusion}

This study provided a glimpse into to the classroom community to exemplify what types of mathematical practices they developed and how they did it as they worked on the topic of three-dimensional shapes, in particular prisms and cylinders. It was observed that the prior establishment of social norms played a critical role in the development of mathematical practices. The critical social norms that underpinned this study were giving examples, explaining, or justifying those examples or solutions with using proper language, constructing a conceptual understanding of solutions or specific concepts, and asking questions. These norms were valuable and the participating teacher played a key role to promote their development.

When the learning process of the students, in the context of three-dimensional shapes, was considered through the mathematical practices that they developed, it was evidently seen that the students improved their conceptual understanding of three-dimensional shapes by participating in discursive activities of the instruction. Their ability of argumentation appeared to improve as well. These findings are consistent with the literature that suggests that the nature of interaction increases the opportunities for student discourse and participation, ultimately improving conceptual understanding (Asterhan \& Schwarz, 2007; Fukawa-Connelly \& Silverman, 2015; Prusak, Hershkowitz, \& Schwarz, 2012; Sadler \& Fowler, 2006; Wood \& McNeal, 2003). Furthermore, the research supported that conducting whole-class discussions including argumentation between the members of the classroom improved the participants' way of commenting on other's ideas more scientifically, accepting or refuting others' comments on the basis of evidence rather than vague statements (Flores, Park, \& Bernhardt, 2016). 
The results of the current study support that social interaction between classroom members affect how children construct mathematical knowledge and establish mathematical practices (Wood, Williams, \& McNeal, 2006). The presence of the social dimension provided opportunities for students to communicate their intended meaning of thought, exchange ideas on different solutions, and ultimately try to convince each other. At the same time, students extended their discussions to a new and difficult situation, resulting in the taken-as-shared ideas of the classroom (Sfard, 2008).

To summarize, according to the findings of the study, it can be stated that the participating students could involve in the instructional activities by reasoning, justifying, and commenting on ideas of others in mathematically acceptable ways. By this way, they could develop a conceptual and meaningful understanding of the threedimensional shapes (specifically for prisms and cylinder for this study). The results of the study supported that the students' conceptual understanding and reasoning ability was enhanced by using a DGS within an argumentative classroom environment.

The mathematical practices of this study can offer a perspective for other researchers who want to study about surface area and/or volume of three-dimensional shapes in a similar learning environment. Finally, it is important to state that these practices were extracted in an environment where social norms were established and sustained. Future studies might focus on how these social norms develop and change across participants in technology and inquiry-based classrooms.

\section{References}

Adolphus, T. (2011). Problems of teaching and learning of geometry in secondary schools in Rivers State, Nigeria. International Journal of Emerging Sciences, 1(2), 143-152.

Akyuz, D. (2016). Mathematical practices in a technological setting: A design research experiment for teaching circle properties. International Journal of Science and Mathematics Education, 14(3), 549-573.

Asterhan, C. S., \& Schwarz, B. B. (2007). The effects of monological and dialogical argumentation on concept learning in evolutionary theory. Journal of Educational Psychology, 99(3), 626-639.

Ayalon, M., \& Hershkowitz, R. (2018). Mathematics teachers' attention to potential classroom situations of argumentation. The Journal of Mathematical Behavior, 49, 163-173.

Battista, M. T. (2007). The development of geometric and spatial thinking. Second handbook of research on mathematics teaching and learning, 2, 843-908.

Brown, R. (2017). Using collective argumentation to engage students in a primary mathematics classroom. Mathematics Education Research Journal, 29(2), 183-199.

Clements, D. H. (1999). Geometric and spatial thinking in young children. In J. V. Copley (Ed.), Mathematics in the early years (pp. 66-79). Reston, VA: National Council of Teachers of Mathematics.

Clements, D. H., Sarama, J., Yelland, N. J., \& Glass, B. (2008). Learning and teaching geometry with computers in the elementary and middle school. In M. K. Heid \& G. Blume (Eds.), Research on Technology in the Learning and Teaching of Mathematic, volume 1: research syntheses (pp. 109-154). Greenwich, CT: Information Age.

Cobb, P. (2000). Conducting classroom teaching experiments in collaboration with teachers. In A. Kelly \& R. Lesh (Eds.), Handbook of research design in mathematics and science education (pp. 307-334). Mahwah, NJ: Lawrence Erlbaum Associates, Inc..

Cobb, P. (2003). Investigating students' reasoning about linear measurement as a paradigm case of design research. In M. Stephan, J. Bowers, P. Cobb, \& K. Gravemeijer (Eds.), Supporting students' development of measuring conceptions: Analyzing students' learning in social context (pp. 1-16). Reston, VA: National Council of Teachers of Mathematics.

Cobb, P., Stephan, M., McClain, K., \& Gravemeijer, K. (2011). Participating in classroom mathematical practices. In A. Sfard, E. Yackel, K. Gravemeijer, \& P. Cobb (Eds.), Journey in mathematics education research (pp. 117-782163). Netherlands: Springer. 
Cobb, P., \& Yackel, E. (1996). Constructivist, emergent, and sociocultural perspectives in the context of developmental research. Educational Psychologist, 31(3-4), 175-190.

Cobb, P., Yackel, E., \& McClain, K. (2012). Symbolizing and communicating in mathematics classrooms: Perspectives on discourse, tools, and instructional design. Routledge.

Cobb, P., Yackel, E., \& Wood, T. (1992). A constructivist alternative to the representational view of mind in mathematics education. Journal for Research in Mathematics Education, 23(1), 2-33.

Denbel, D. G. (2015). Students' learning experiences when using a dynamic geometry software tool in a geometry lesson at secondary school in Ethiopia. Journal of Education and Practice, 6(1), 23-38.

Duval, R. (2000). Basic issues for research in mathematics education. In T. Nakahara \& M. Koyama (Eds.), Proceedings of the 24th Conference of PME, 1 (pp. 55-69). Hiroshima: Nishiki Print Co. Ltd..

Erkek, Ö., \& Bostan, M. I. (2019). Prospective middle school mathematics teachers' global argumentation structures. International Journal of Science and Mathematics Education, 17(3), 613-633.

Flores, A., Park, J., \& Bernhardt, S. A. (2016). Learning mathematics and technology through inquiry, cooperation, and communication: A learning trajectory for future mathematics teachers. In M. Niess, S. Driskell, \& K. Hollebrands (Eds.), Handbook of Research on Transforming Mathematics Teacher Education in the Digital Age (pp. 324-352). Hershey, PA: IGI Global.

Fraenkel, J. R., Wallen, N. E., \& Hyun, H. (2014). How to design and evaluate research in education. New York, NY: McGraw-Hill.

Fukawa-Connelly, T., \& Silverman, J. (2015). The development of mathematical argumentation in an unmoderated, asynchronous multi-user dynamic geometry environment. Contemporary Issues in Technology and Teacher Education, 15(4), 445-488.

Graveimejer, K. \& Cobb, P. (2013). Design research from a learning design perspective. Educational design research. In T. Plomp \& N. Nieveen (Eds.), Educational design research - Part A: An Introduction (pp. 73-112). Enschede, the Netherlands: SLO.

Gutiérrez, A. (1996). Visualization in 3-dimensional geometry: In search of a framework. In L. Puig \& A. Gutierrez (Eds.), Proceedings of the 20th PME International Conference, 1 (pp. 3-19). Valencia: University of Valencia.

Hollebrands, K. F. (2007). The role of a dynamic software program for geometry in the strategies high school mathematics students employ. Journal for Research in Mathematics Education, 38(2), 164-192.

Kosko, K. W., Rougee, A., \& Herbst, P. (2014). What actions do teachers envision when asked to facilitate mathematical argumentation in the classroom? Mathematics Education Research Journal, 26(3), 459476.

Krummheuer, G. (1995). The ethnography of argumentation. Hillsdale: Lawrance Erlbaum Assoc., Inc.

Krummheuer, G. (2007). Argumentation and participation in the primary mathematics classroom: Two episodes and related theoretical abductions. The Journal of Mathematical Behavior, 26(1), 60-82.

Krummheuer, G. (2015) Methods for reconstructing processes of argumentation and participation in primary mathematics classroom interaction. In A. Bikner-Ahsbahs, C. Knipping, \& N. Presmeg (Eds.), Approaches to qualitative research in mathematics education. Advances in mathematics education (pp. 51-74). Dordrecht: Springer.

Laborde, C., Kynigos, C., Hollebrands, K., \& Strässer, R. (2006). Teaching and learning geometry with technology. In A. Gutierrez \& P. Boero (Eds.), Handbook of research on the psychology of mathematics education: Past, present, and future (pp. 275-304). Rotterdam: Sense Publishers.

Leung, A. (2011). An epistemic model of task design in dynamic geometry environment. ZDM, 43(3), 325336.

Mason, M. (1998). The van Hiele levels of geometric understanding. In L. McDougal (Ed.), The professional handbook for teachers: Geometry (pp. 4-8). Boston: McDougal-Littell/Houghton-Mifflin.

Morgan, C., \& Alshwaikh, J. (2012). Communicating experience of 3D space: Mathematical and everyday discourse. Mathematical Thinking and Learning, 14(3), 199-225.

Moschkovich, J. N. (2002). An introduction to examining everyday and academic mathematical practices. In M. Brenner \& J. Moschkovich (Eds.), Everyday and academic mathematics in the classroom (pp. 1-11). Reston, VA: National Council of Teachers of Mathematics.

Mueller, M., Yankelewitz, D., \& Maher, C. (2014). Teachers promoting student mathematical reasoning. Investigations in Mathematics Learning, 7(2), 1-20.

Ng, O., \& Sinclair, N. (2015). Area without numbers: Using touchscreen dynamic geometry to reason about shape. Canadian Journal of Science, Mathematics, and Technology Education, 15(1), 84-101.

Oldknow, A., \& Tetlow, L. (2008). Using dynamic geometry software to encourage 3D visualization and modeling. The Electronic Journal of Mathematics and Technology, 2(1), 54-61.

Owens, K. (2014). Diversifying our perspectives on mathematics about space and geometry: An ecocultural approach. International Journal of Science and Mathematics Education, 12(4), 941-974. 
Plomp, T. (2013). Educational design research: An introduction. In T. Plomp \& N. Nieveen (Eds.), Educational design research - Part A: An Introduction (pp. 10-51). Enschede, the Netherlands: SLO.

Prusak, N., Hershkowitz, R., \& Schwarz, B. B. (2012). From visual reasoning to logical necessity through argumentative design. Educational Studies in Mathematics, 79(1), 19-40.

Rasmussen, C., \& Stephan, M. (2008). A methodology for documenting collective activity. In A. E. Kelly, R. A. Lesch, \& J. Y. Baek (Eds.), Handbook of design research methods in education: Innovations in science, technology, engineering, and mathematics learning and teaching (pp. 195-215). New York: Routledge.

Sack, J. J. (2013). Development of a top-view numeric coding teaching-learning trajectory within an elementary grades 3-D visualization design research project. The Journal of Mathematical Behavior, 32(2), 183-196.

Sadler, T. D., \& Fowler, S. R. (2006). A threshold model of content knowledge transfer for socioscientific argumentation. Science Education, 90(6), 986-1004.

Saxe, G. B., de Kirby, K., Le, M., Kang, B., \& Sitabkhan, Y. (2015). Understanding learning across lessons in classroom communities: A multi-leveled analytic approach. In A. Bikner-Ahsbahs, G. Kaiser, \& N. Presmeg (Eds.), Approaches to qualitative research in mathematics education (pp. 253-318). Dordrecht, The Netherlands: Springer.

Schwarz, B. B., Hershkowitz, R., \& Prusak, N. (2010). Argumentation and mathematics. In C. Howe \& K. Littleton (Eds.), Educational dialogues: Understanding and promoting productive interaction (pp. 115141). London: Routledge.

Simon, M. (1995). Reconstructing mathematics pedagogy from a constructivist perspective. Journal for Research in Mathematics Education, 26(2), 114-145.

Sfard, A. (2008). Thinking as communicating: Human development, the growth of discourses, and mathematizing. Cambridge: Cambridge University Press.

Stephan, M. (2015). Surface area.https://cstem.uncc.edu/sites/cstem.uncc.edu/files/media/files/stephan_ surface_area.pdf. Accessed 3 Aug 2016.

Stephan, M., \& Akyuz, D. (2012). A proposed instructional theory for integer addition and subtraction. Journal for Research in Mathematics Education, 43(4), 428-464.

Stephan, M., \& Rasmussen, C. (2002). Classroom mathematical practices in differential equations. The Journal of Mathematical Behavior, 21(4), 459-490.

Toulmin, S. E. (1969). The uses of argument. Cambridge: The University Press.

Wood, T., \& McNeal, B. (2003). Complexity in teaching and children's mathematical reasoning. In N. A. Pateman, B. J. Dougherty, \& J. Zilliox (Eds.), Proceedings of the 27th conference of the International Group for the Psychology of Mathematics Education (Vol. 4, pp. 435-441). Honolulu, HI: University of Hawai'i.

Wood, T. \& Turner-Vorbeck, T. (2001). Extending the conception of mathematics teaching. In T. Wood (Ed.), Beyond classical pedagogy teaching elementary school mathematics (pp. 185-208). Mahwah, NJ: Lawrence Erlbaum Associates.

Wood, T., Williams, G., \& McNeal, B. (2006). Children's mathematical thinking in different classroom cultures. Journal for Research in Mathematics Education, 37, 222-252.

Wright, V., \& Smith, K. (2017). Children's schemes for anticipating the validity of nets for solids. Mathematics Education Research Journal, 29(3), 369-394.

Yackel, E. (2001). Explanation, justification and argumentation in mathematics classrooms. In M. Van den Heuvel-Panhuizen (Ed.), Proceedings of the 25th conference of the international group for the psychology of mathematics education PME-25 (Vol. 1, pp. 1-9). Utrecht (Olanda).

Yackel, E., \& Cobb, P. (1996). Sociomathematical norms, argumentation, and autonomy in mathematics. Journal for Research in Mathematics Education, 27(4), 458-477. 